\title{
Current Research Areas in Blockchain
}

\author{
Yılmaz Dikilitaş ${ }^{1 *}$, Kazım Onur Toka ${ }^{2}$, Ahmet Sayar ${ }^{3}$ \\ ${ }^{1}$ Kocaeli Üniversitesi, Mühendislik Fakültesi, Bilgisayar Mühendisliği Bölümü, Kocaeli, Türkiye, (ORCID: 0000-0002-8892-574X), yilmaz.dikilitas@kocaeli.edu.tr \\ ${ }^{2}$ Kocaeli Üniversitesi, Mühendislik Fakültesi, Bilgisayar Mühendisliği Bölümü, Kocaeli, Türkiye, (ORCID: 0000-0003-2070-9036), kazim.onurtoka@gmail.com \\ ${ }^{3}$ Kocaeli Üniversitesi, Mühendislik Fakültesi, Bilgisayar Mühendisliği Bölümü, Kocaeli, Türkiye, (ORCID: 0000-0003-2070-9036), asayar@gmail.com
}

(International Congress on Human-Computer Interaction, Optimization and Robotic Applications (HORA) 2021 - 11-13 June 2021)

(DOI: 10.31590 /ejosat.977320)

ATIF/REFERENCE: Dikilitaş, Y., Toka, K. O. \& Sayar, A. (2021). Current Research Areas in Blockchain. Avrupa Bilim ve Teknoloji Dergisi, (26), 488-492.

\begin{abstract}
A blockchain is a digital record of transactions. The name comes from its structure, in which individual records, called blocks, are linked together in single list, called a chain. It stands out with the rise of Bitcoin. Its popularity is increasing day by day. It provides anonymity, privacy and data integrity without any control organization. In this report, we will reveal the areas of research that have emerged. We will touch on what these research areas can bring forward. Articles are generally related to Bitcoin. But lately, this technology has entered many areas of our lives. Recommendations on future research directions are provided in this paper.
\end{abstract}

Keywords: Blockchain, Research, Supply Chain, IoT, Finance.

\section{Blok Zincir Güncel Araştırma Alanları}

$\ddot{O} \mathbf{z}$

Blockchain, işlemlerin dijital bir kaydıdır. Blok zincir kavramı, blok adı verilen bireysel kayıtların zincir adı verilen tek bir listede birbirine bağlandığı yapısından gelir. Bitcoin'in yükselişi ile öne çıkan teknolojinin popülaritesi her geçen gün artıyor. Blok zincir, herhangi bir kontrol organizasyonu olmadan anonimlik, gizlilik ve veri bütünlüğü sağlar. Bu raporda, blok zincir teknolojisi çerçevesinde popülerleşen araştırma alanları ortaya konulacaktır. Bu araştırma alanlarının neler getirebileceğine değinilecektir. Son zamanlarda bu teknoloji hayatımızın birçok alanına girdi. Gelecekteki araştırma yönlerine ilişkin öneriler bu makalede sunulmaktadır.

Anahtar Kelimeler: Blok Zincir, Araştırma, Tedarik Zinciri, Nesnelerin Interneti, Finans.

\footnotetext{
${ }^{*}$ Corresponding Author: Kocaeli Üniversitesi, Mühendislik Fakültesi, Bilgisayar Mühendisliği Bölümü, Kocaeli, Türkiye, (ORCID: 0000-00028892-574X), yilmaz.dikilitas@kocaeli.edu.tr
} 


\section{Introduction}

Today, transactions are controlled by the central systems. These systems are required to make transactions. They charge additional fees for most of these transactions. This additional fee applies to many transaction cases. Blockchain has been developed to solve this problem. The aim is to establish a decentralized structure in which this other organization cannot control transactions and data.

Initially, blockchain's key application was to connect cryptocurrencies to traditional banking and financial institutions. Blockchain technology creates a new banking environment, allowing financial institutions to perform transactions directly between themselves without the need for central authorities or intermediaries. Per transaction must be authenticated by the agreement of at least half of the network participants. This ensures that no participant can change any data on the blockchain without the permission of other participants.

A blockchain is a distributed ledger that keeps track of transactions. The name comes from the structure of the database, which consists of individual records connected together in chain. Blockchains are used to monitor cryptocurrency transactions, such as Bitcoin, and have a variety of other uses. A peer-to-peer network is formed by these systems, which are designed to track particular types of blockchain transactions. Until a transaction is added to the blockchain, they collaborate to ensure that it is true.

Following the Bitcoin currency, other digital currencies such as Ethereum and Dogecoin have appeared, both of which are based on the same technology as Bitcoin. Despite the fact that the blockchain has a wide range of applications.

We believe it is important to recognise other blockchain application areas in light of the blockchain's recent popularity as the key technology behind digital currencies such as Bitcoin.

To the best of our knowledge, there is no formal overview of the existing and future blockchain applications, and the current work's main goal is to include such an overview.

As previously mentioned, one of the main goals of the current project is to define various blockchain implementation areas. Another aim of our research is to find possible blockchain technology areas in the future.

The outline of the study is as follows, summary information about blockchain is included in section 2.1., In section 2.2. the work done on blockchain summarized. In section 3 , research areas in blockchain is discussed and in section 4 provides conclusions.

\section{Material and Method}

\subsection{Background}

Since the publication of the Bitcoin whitepaper (Nakamoto, 2008: 9) in 2008, blockchain systems have sparked a lot of interest. Bitcoin's security is based on a distributed protocol that keeps track of transactions in a distributed ledger. By iterating over nonce field values, protocol miners attempt to find a partial hash collision in order to produce a valid block. The blockchain network has no central authority, making it the epitome of a democratic structure. The knowledge in it is available to everyone because it is a shared and immutable ledger. As a result, everything built on the blockchain is transparent by definition, and anyone involved is accountable.

The blockchain is a simple but clever way of sending data from point $\mathrm{A}$ to point $\mathrm{B}$ in a completely automated and secure manner. Transaction requests executed on the blockchain network continue until a block is filled. When it receives a transaction request as much as a block capacity, the block creation process starts. In the process of creating a new block, a math problem is tried to be solved by the miners who are the participants of the network. When the math problem is solved, the new block is added to the blockchain with a consensus provided by the entire network. The validated block is attached to a chain that is stored around the internet, resulting in a record that is not only unique, but also has a unique history. In millions of cases, falsifying a single record will mean falsifying the entire chain. That's almost unthinkable. This model is used in Bitcoin for monetary transactions, but it can also be used in a variety of other ways.

Stuart Haber and W. Scott Stornetta (Haber and Stornetta, 1991: 13) envisioned what many people have come to know as blockchain, in 1991. Their first work involved working on a cryptographically secured chain of blocks whereby no one could tamper with timestamps of documents.In 1992, they upgraded their system to incorporate Merkle trees that enhanced efficiency thereby enabling the collection of more documents on a single block. However, it is in 2008 that Blockchain History starts to gain relevance, thanks to the work one person or group by the name Satoshi Nakamoto.

Satoshi Nakamoto (Nakamoto, 2008: 9) is accredited as the brains behind blockchain technology. Very little is known about Nakamoto as people believe he could be a person or a group of people that worked on Bitcoin, the first application of the digital ledger technology. Nakamoto conceptualized the first blockchain in 2008 from where the technology has evolved and found its way into many applications beyond cryptocurrencies. Satoshi Nakamoto released the first whitepaper about the technology in 2009. In the whitepaper, he provided details of how the technology was well equipped to enhance digital trust given the decentralization aspect that meant nobody would ever be in control of anything.

The three main properties of blockchain technology which have helped it gain widespread acclaim are as follows; decentralization, transparency, immutability.

In blockchain, decentralization means the transfer of control and decision-making from a centralized entity to a distributed network. Decentralized networks aim to minimize the amount of trust that participants must put in one another and to prevent them from exerting authority or power over one another in ways that damage the network's functionality.

Enabling transparency of information is one of the biggest promises of blockchain technology, which provides a fully auditable and valid ledger of transactions. Blockchain is supposed to be a transparency machine in which anyone can join the network and, as a result, view all information on that network. Through the necessary encryption and control mechanisms, blockchain safeguards transparency by storing information in 
such a way that it cannot be altered without recording the changes made.

\subsection{Related Works}

In this section, relevant studies conducted within the scope of research areas in blockchain will be discussed.

At (Yli-Huumo vd., 2016: 11), the current research areas of blockchain are given according to the numerical research conducted on the articles.According to these articles, information on the direction of the studies conducted on a percentage basis and what feature of the blockchain is given.There is no explanation of the disadvantages that blockchain may bring, and then it has been shown which areas may become more prominent in the future.

At (Wang vd., 2019: 191), the applications of blockchain as an intellectual property have been demonstrated. According to the academic research and industry practices in this field, it has been shown which areas may come to the fore in the future.

At (Xu vd., 2019: 27), it has been shown that blockchain technology is still new. A systematic review of the most cited articles in this area by searching with important keywords is done. In addition, some research themes are emphasized by clustering analysis. Inferences from this are recommendations for future research directions.

At (Tama vd., 2017: 109) , after explaining the general features of blockchain, 26 of the articles searched with blockchain keyword on google scholar were taken as a sample.Later, by inferring from these articles, the future research areas of blockchain are given direction. Focused on were examined.

At (Lage vd., 2019: 239) examines the work of blockchain in the field of cybersecurity. By analyzing these, it shows that blockchain has brought many innovations in terms of security. At the end of the systematic review, it shows the future aspects of research, education and applications in the field of security of blockchain.

Blockchain is a very rapidly developing technology, the articles mentioned above are outdated. They are generally written on the basis of academic articles. This study is not only new, but also examines the resources on the web.

\section{Results and Discussion}

\subsection{Research Directions of Blockchain}

In this section, the implementation of blockchain technology in different areas are thoroughly discussed. Furthermore, such applications have been categorized into several groups, i.e. financial services, healthcare, business and industry, and other novel applications.

\subsubsection{Finance}

The blockchain technology has been commonly used for financial transactions called cryptocurrency. Cryptocurrencies are becoming prominent software systems in recent years. Cryptocurrency is a form of online payment that can be used to buy and sell products and services. Many businesses have created their own currencies, known as tokens, that can be exchanged for the goods or services that the business offers. To use the product or service, you'll need to trade real money for cryptocurrency.
According

to

Coinmarketcap.com \{https://coinmarketcap.com/\}, a market analysis website, more than 9,700 separate cryptocurrencies are publicly traded. And cryptocurrencies continue to grow in popularity, with initial coin offerings, or ICOs $\{$ https://icodrops.com/ $\}$, being used to raise funds. According to CoinMarketCap, the total value of all cryptocurrencies was more than 2.2 trillion dollars on April 29, 2021, and the total value of all bitcoins, the most common digital currency, was more than 1 trillion dollars.

Transaction, loan, mortgage, and payment services are all part of core banking. Many of these services depend on legacy execution processes. Individuals can get a mortgage in 30 to 60 days, and small and medium businesses can get a business loan in 60 to 90 days, depending on information confirmation, credit scoring, loan processing, and distribution of funds (Yoo, 2017: 312).Blockchain has the potential to simplify banking and lending services by lowering counterparty risk and reducing issuance and settlement times.

\subsubsection{Healthcare}

In terms of healthcare, private networks are now more advanced than public networks. This is one place where blockchain technology has the potential to change things. It is capable of a wide range of tasks, including secure encryption of patient data and the mitigation of epidemics. Estonia is a pioneer in this area, having implemented blockchain technology in healthcare in 2012.Currently, blockchain is used to manage all healthcare billing, 95 percent of health records, and 99 percent of medication details (Sandner, 2020). The following are some of the major issues with blockchain implementations in healthcare;network infrastructure security,Identity verification and authentication and authorization to access electronic health information.

The benefits of using blockchains, relative to traditional methods of healthcare database management systems, include decentralized management, unchangeable databases, data provenance, traceable data, robust data, availability of data to any authorized user, while keeping it out of the hands of unauthorized users by encryption that is dependent on a patient's private key.

\subsubsection{Smart Contracts}

Smart contracts are simply programs stored on a blockchain that run when predetermined conditions are met. They are usually used to simplify the execution of an agreement so that both parties can be confident of the result right away, without the need for any intermediaries or time waste. They can also automate a workflow, starting the next step when those conditions are met (Ante, 2020: 48).

Simple statements are written into code on a blockchain to make smart contracts work. When predetermined conditions are met and tested, the activities are carried out by a network of computers. These activities could include transferring funds to the proper parties, registering a car, sending notifications, or issuing a ticket.When the transaction is complete, the blockchain is modified. That means the transaction can not be reversed, and the results are only visible to those who have been given permission.

Benefits of smart contracts are efficiency,accuracy,transparency and security. Because of this benefits most companies looking to integrate blockchain to their operations. 


\subsubsection{Business}

For companies transacting with one another, blockchain for business is useful. Permissioned users can access the same information at the same time using distributed ledger technology, which improves performance, builds confidence, and reduces friction.Blockchain also enables a solution's size and scale to be quickly adjusted, and several solutions can be modified to perform various tasks across industries (Konstantinidis vd., 2018: 384).

Businesses benefit from blockchain in the following ways;operational cost reduction,easy tracking of transactions, transparency, authenticity, reliability, and security.

One of the most significant advantages of blockchain technology is the ability to lower operating costs. Since blockchain eliminates intermediaries and the manual effort associated with transaction reconciliation and record-keeping, companies can save time and money.Furthermore, blockchain allows companies to securely track goods and transactions back to their source.Finally, blockchain technology offers greater accountability, authenticity, and reliability. This is due to the fact that it is secured, making all transactions more secure and allowing for the tracking and documentation of all aspects of the transactions.

\subsubsection{Internet of Things}

The Internet of Things (IoT) connects people, places, and things, creating opportunities for value creation and capture. Objects are embedded with sophisticated chips, sensors, and actuators, each of which transmits data to the IoT network. The IoT's analytics capabilities transform this data into reality, affecting business processes and resulting in new ways of working. There are, however, a number of technological and security issues that have yet to be resolved (Deloitte, 2021).

In the event of a cyber-attack, the IoT network will process data transactions through various devices owned and managed by different organizations, making it impossible to trace the source of any data leakages. Furthermore, the IoT produces a large amount of data, and the ownership of that data is not always transparent due to the various stakeholders involved.

Using blockchain to store IoT data would provide an additional layer of encryption that hackers would have to get around to gain access to the network. The blockchain technology offers a much higher degree of encryption, making it almost impossible to overwrite existing data records. Blockchain offers transparency by allowing anyone with permission to access the network to view and monitor previous transactions. This can be a reliable way to pinpoint the root of any data leaks and take immediate corrective steps.

\subsubsection{Supply Chains}

A supply chain is a collection of organisations, individuals, activities, knowledge, and resources involved in getting a product or service from the supplier to the consumer. It's made to keep important products in good condition during the shipping process. Corruption, fraud, and tampering are all risks associated with centralized supply chain management systems (AltexSoft, 2021). Blockchain is a modern distributed information system that reflects a new solution in the supply chain, where visibility and accountability of commodity flows are major challenges.
There are benefits of blockchain in a suppy chain. Improved protection and traceability. There can be no documents lost, destroyed, or replaced. Furthermore, a blockchain-based framework removes the possibility of false identifiers being used to steal documents or products. Transactions are safer and more straightforward, resulting in increased confidence for all parties involved; there is less manual work and no paperwork delays. All the agreement conditions can be met by machine, without any human interference, thanks to smart contracts.

\section{Conclusions and Recommendations}

The Bitcoin cryptocurrency is driven by blockchain technology. It is a decentralized transaction environment in which all transactions are registered in a public ledger that is open to everyone. The aim of Blockchain is to provide all of its users with anonymity, protection, privacy, and transparency.

To understand where the current research on Blockchain technology we searched papers, websites and we extract information from there. We discussed the areas where blockchain has increased in usage recently. By describing these areas, we showed the benefits of this technology in these areas.

\section{References}

Nakamoto, S. (t.y.). Bitcoin: A Peer-to-Peer Electronic Cash System. 9.

Haber, S., \& Stornetta, W. S. (t.y.). How to time-stamp a digital document. 13.

Yli-Huumo, J., Ko, D., Choi, S., Park, S., \& Smolander, K. (2016). Where Is Current Research on Blockchain Technology?-Systematic Review. PLOS ONE, 11. https://doi.org/10.1371/journal.pone.0163477

Wang, J., Wang, S., Guo, J., Du, Y., Cheng, S., \& Li, X. (2019). A Summary of Research on Blockchain in the Field of Intellectual Property. Procedia Computer Science, 147, 191197. https://doi.org/10.1016/j.procs.2019.01.220

Xu, M., Chen, X., \& Kou, G. (2019). A systematic review of blockchain. Financial Innovation, 5(1), 27. https://doi.org/10.1186/s40854-019-0147-z

Adhi Tama, B., Kweka, B., Park, Y., \& Rhee, K. H. (2017). A critical review of blockchain and its current applications. 109113. https://doi.org/10.1109/ICECOS.2017.8167115

Lage, O., de Diego, S., Urkizu, B., Gómez, E., \& Gutiérrez Agüero, I. (2019). Blockchain Applications in Cybersecurity. https://doi.org/10.5772/intechopen.90061

Yoo, S. (2017). Blockchain based financial case analysis and its implications. Asia Pacific Journal of Innovation and Entrepreneurship, 11(3), 312-321. https://doi.org/10.1108/APJIE-12-2017-036

Sandner, P. (2020, Mayıs 19). Blockchain in Healthcare. Medium. https://philippsandner.medium.com/blockchain-inhealthcare-fbbd2989a9dc

Ante, L. (2020). Smart Contracts on the Blockchain-A Bibliometric Analysis and Review.

Konstantinidis, I., Siaminos, G., Timplalexis, C., Zervas, P., Peristeras, V., \& Decker, S. (2018). Blockchain for Business Applications: A Systematic Literature Review (ss. 384-399). https://doi.org/10.1007/978-3-319-93931-5_28

Can blockchain accelerate Internet of Things (IoT) adoption. (t.y.). Deloitte Switzerland. Geliş tarihi 09 Mayıs 2021, gönderen 


\section{Avrupa Bilim ve Teknoloji Dergisi}

https://www2.deloitte.com/ch/en/pages/innovation/articles/b lockchain-accelerate-iot-adoption.html

Blockchain in Supply Chain and Transportation: Benefits and Use
Cases | AltexSoft. (t.y.). Geliş tarihi 09 Mayıs 2021, gönderen https://www.altexsoft.com/blog/blockchain-supply-chain/ 